\title{
The use of ICT and distance learning technologies in teaching
}

\author{
I.A. Petrozitskaya ${ }^{1 *}$, I.I. Elkina ${ }^{2}$, and E.F. Mazanyuk ${ }^{3}$ \\ ${ }^{1}$ Crimean branch of the Krasnodar University of the MIA of Russia, Simferopol, Russia \\ ${ }^{2}$ V.I. Vernadsky Crimean Federal University, Simferopol, Russia \\ ${ }^{3}$ V.I. Vernadsky Crimean Federal University, Simferopol, Russia
}

\begin{abstract}
This article is devoted to the use of distance learning technologies in teaching. The authors also distinguish the features of learning using distance learning methods. The authors note that the rapid development of information and communication technologies and the use of e-learning have expanded the possibilities of the educational process and provided opportunities for the general development of students. Practice shows that the use of electronic educational resources improves students' perception and understanding of the discussed issues, creates more comfortable conditions for learning. However, by means of the systematic use of electronic educational resources in the educational process in combination with traditional teaching methods and pedagogical innovations, the effectiveness of multilevel education has significantly increased. At the same time, there is a qualitative increase in educational results due to the simultaneous impact of several technologies.
\end{abstract}

\section{A problem statement}

The urgency of the research is due to the fact that at the present stage, in order to respond to new challenges, the state endeavours to modernize the education system. One of the ways of updating is the application of the results of information technologies in education. Informatization of education is an integral part of the general historical process of informatization of world society, with the aim of changing the quality of education through the active use of modern information technologies and additional educational resources to enhance the role of independent learning.

With the adoption and implementation of federal state educational standards, the results of the implementation of basic educational programs, the requirements for the conditions of achievement and the structure of basic general educational programs have been also changed, which would have been impossible without the existence of an information educational environment, the widespread use of information technologies and electronic educational resources. The new federal state educational standards require teachers to use ICT in the educational process and, thus, to teach students the effective and reasonable use of ICT. The traditional education system has repeatedly made personal teaching methods

${ }^{*}$ Corresponding author: prof-ped.gpa@mail.ru 
priority and dominant. In practice, however, it is very difficult to realize individualized methods in traditional schools. Educational institutions currently set the introduction of distance technologies into the educational process as one of the priority tasks of their work. In the process of distance learning, it is much easier to implement an individual approach to learning, taking into account the abilities, interests and personal daily life of a student [1].

The federal target plan for the development of education for the period up to 2020 provides the formation of a new technical environment in the education system for the development of distance education and educational services for students, including people with disabilities, children and people living in remote areas.

As an experiment more than 20 years ago (The Order of the Ministry of Education and Science of the Russian Federation dated on 05.30.1997 № 1050), distance learning has gradually developed over the years. Since 2014 the legislation of the Russian Federation (The Order of the Ministry of Education and Science of the Russian Federation dated on 01.09.2014 № 2) established the right to use distance technologies during the current and final certification of students in higher educational institutions.

The use of distance learning or its elements within the framework of specific academic disciplines and curricula of general education institutions can arouse the interest of children living in the information society, and generate a desire to use information technology for studying this subject.

Despite the legislative support and modern requirements, the introduction of distance learning is associated with 5 certain difficulties: lack of teachers, imperfect material and technical base, lack of software, methodological and information support, etc.

That is why a contradiction arises between the need of introducing the distance learning into the educational process and the lack of conditions for the implementation of this area of activity.

The purpose of this article is to study distance learning technologies in pedagogical activities in the Russian Federation and ways of their further improvement in our days.

The methods of the research: theoretical methods - the exploration and analysis of literature on the research problem, the system analysis of the main research concepts; practical methods - the methods of scientific analysis and modeling, statistical processing of information.

As it was noted right by E.S. Polat, the goal of informatization of education in the country is to change the content, methods and forms of organizing educational work in the context of the formation of schools aimed at meeting the needs of young people in life in an information society, at the same time, "life not only makes new demands on schools, but also provides schools with tools for solving new problems": new teaching methods and information and communication technologies (ICT) tools to support them [2].

Distance learning based on new technologies uses all the experience gained in the field of distance education. New information and communication technologies are used for distance learning. These methods, combined with theory and practice, become a new quality, "knowledge environment" [3]. For example, distance learning is understood as pedagogical activity in which interaction between the teacher and students takes place, as well as interactive information resources (for example, websites or web pages) reflecting all components of the educational process (goals, content, methods, organizational forms, educational institutions).

According to A.A. Andreev "distance learning is an educational process in which the interaction of a teacher and a student occurs at a distance through various types of mediated communication. Indirect communication is a two-way exchange of information in the form of text, audio or video recordings, tables, images, etc." [4]. 
According to the analysis of the literature on the research issues, it is worth noting that distance learning can affect the solution of socio-economic problems in various regions through distance virtual education, in particular:

- in conditions of free access to education, information and texts;

- creation of a system of continuous postgraduate education, advanced training and retraining of personnel on a part-time basis;

- creation of additional channels of information support for teachers who carry out retraining and advanced training [5].

A.V. Nevzorova identified the following features of distance learning [6]:

1. Flexibility: learners (listeners) use teaching materials at a convenient time, in a convenient place, at a convenient speed.

2. Modularity: every modular course creates a general understanding of a specific subject area. This allows you to create courses that meet the specific needs of students from a separate set of module courses.

3. Economic Efficiency: the relatively low cost of training is due to the introduction of distance learning methods for a large number of students and more efficient use of educational space and technical means, for example, on weekends and holidays.

4. The new role of teachers: in fact, teachers are acting as mentors. Distance learning is entrusted with such functions as the coordination of cognitive processes, the correction of the taught courses. It helps students to build personal educational trajectories, perform various types of certification work and helps to solve academic and personal problems associated with learning. The educational process using DLT is often characterized by asynchronous interaction between participants.

5. Professional quality control of education: remotely organized exams, interviews, project work and computer test systems are used as a form of control.

6. The use of specialized methods and teaching aids: under the technology of distance learning we mean a set of methods, forms and means of interaction with the audience in the process of independent, but controlled mastering of certain knowledge.

7. The dependence on the means of transmission of modern educational information: the "central" link in the distance education system is the means of communication and its transport basis (Figure 1).

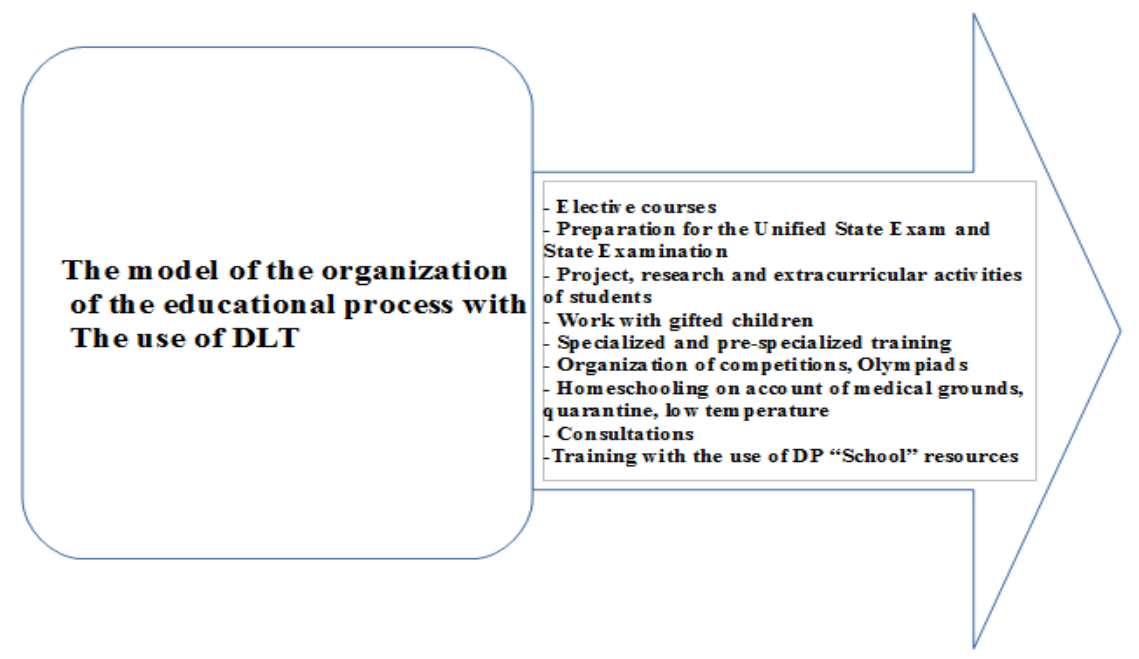

Fig. 1. Variants of the model of the educational process, organized with the help of ICT. 


\subsection{The objective of the work}

During the teaching practice, the students of the Federal State Autonomous Educational Institution of Higher Education "V.I. Vernadsky Crimean Federal University" conducted a survey among students of the 9th form by questioning "What is your attitude to independent remote work?"

A total of 65 people took part in the survey. The survey results are shown in Table 1. The purpose of this study is to identify existing problems in the field of information technology, to study existing strategies for the implementation of such technologies in the organizational and management mechanisms of educational institutions, as well as to analyze the experience of using such technologies in practice.

Table 1. Results of the questionnaire "What is your attitude to independent work?", $\%$ of students.

\begin{tabular}{|l|l|l|}
\hline \multicolumn{1}{|c|}{ Questionnaire questions } & $\begin{array}{c}\text { The answer } \\
\text { "yes" }\end{array}$ & $\begin{array}{c}\text { The answer } \\
\text { "no" }\end{array}$ \\
\hline $\begin{array}{l}\text { Do you know how to organize your independent work in a right } \\
\text { way? }\end{array}$ & 35.2 & 45.0 \\
\hline Can you allocate your time correctly while doing the task? & 46.5 & 65.8 \\
\hline Does your independent work help you to get knowledge? & 46.5 & 53.5 \\
\hline $\begin{array}{l}\text { When performing independent work is it enough for you to use the } \\
\text { action algorithm and methodological recommendations of the } \\
\text { Internet sites proposed by teachers? }\end{array}$ & 34.2 & 65.8 \\
\hline $\begin{array}{l}\text { Would you like to receive real help, immediate guidance from a } \\
\text { teacher when doing your independent work? }\end{array}$ & 81.0 & 19.0 \\
\hline $\begin{array}{l}\text { Do you experience significant difficulties at the stages of } \\
\text { comprehension, processing, interpretation of the necessary } \\
\text { information when performing independent work? }\end{array}$ & 48.4 & 51.6 \\
\hline $\begin{array}{l}\text { Do you see the benefits of distance learning? } \\
\text { n }\end{array}$ & 63 & 37 \\
\hline
\end{tabular}

The analysis of the questionnaire showed that most of the students were unable to organize extracurricular activities independently. Unfortunately, 37\% of those surveyed said that remote technologies have no advantages. Analysis of student surveys shows that distance learning has its advantages and disadvantages. On the positive side, most learners understand and accept distance learning across a variety of disciplines. They note that this form of study has an individual and flexible schedule, pace, which makes them more confident in gaining knowledge. Students would like to use distance learning as additional, for example, to prepare for current and intermediate control, etc. The complexity of distance learning can be explained by the fact that the technical aspects of courseware are not perfect: students do not know modern computer technologies, the complexity of independent analysis of course materials. $65.8 \%$ of the interviewed respondents answered that in general they feel the lack of the algorithms of actions and methods proposed by the teachers' websites when performing independent work. One of the reasons for this reaction is that the students do not have the skills of using teaching materials independently, which, of course, requires a lot of diligence and time.

\section{Results of the research}

The use of modern ICT tools in all forms of education can also lead to a number of negative consequences, including a number of negative psychological and pedagogical factors and a number of factors that have a negative impact on the physical condition of students. In most cases, one of the benefits of ICT-assisted learning is the personalization of learning. 
However, in addition to the advantages, there are also serious disadvantages associated with full personalization. Personalization shortens the real-time dialogue between the participants in the educational process. In the process of teaching, modern students have to deal with a large variety of educational information. That is why the informational overload and emotional arousal arise, which is dangerous for the physical and mental health of students. The use of information resources often leads to negative consequences. Most often, the principle of energy saving works, which is inherent in all organisms - readymade projects, summaries, reports and solutions to problems borrowed from the Internet have become a common fact today, which does not contribute to an increase in the effectiveness of training and education.

Working at a computer for a long time can negatively affect many functions of the body: higher neurological activity, endocrine and immune systems, vision and the locomotion apparatus of a person. Side effects from working in front of a computer appear:

- children stop fantasizing, become unable to create their own visual images, it is difficult for them to generalize and analyze information;

- computers can lead to long-term obstacles in the field of mental and intellectual development of children, can reduce the function of certain types of memory, contribute to emotional immaturity;

- mental stress causes stress in children;

- virtual reality leads to the loss of the sense of natural danger [7-10].

It is well known that the greatest obstacles to the use of ICT at all levels of education in all countries, regardless of their technological development and equipment with specific educational institutions, are the almost complete lack of development of methods for using ICT in education and the absence or inadequacy of teacher training. For educators, ICTs are most effective when used in the following cases:

- during classes;

- in project activities, when creating materials for courses;

- in the process of scientific activity;

- in the exchange of experience within educational institutions and in interaction with other educational institutions.

For students, information and communication technologies have the greatest effect when used in the following situations:

- in project activities;

- when creating a multimedia composition;

- in demonstration events;

- in local and global networks [10-13].

The use of ICT in teaching requires the solution of many problems so that the formation of the information potential of all participants in the educational process will not be painful and difficult, but creative, purposeful and effective. At the same time, one should not forget that computer technology is just a tool that will never replace a teacher.

Based on the foregoing, we can conclude that in the educational process modern teachers should be able to use electronic teaching aids and information technologies competently and effectively. That is why we believe that organizing independent work using traditional techniques, methods and tools allows you to form reproductive skills: working with models, filling out forms, drawing up diagrams. In the course of the survey many of the respondents noted that they cannot force themselves to perform tasks correctly, they constantly do not have enough time, experience difficulties in perceiving information, and are afraid of making mistakes when completing tasks.

In the modern world the learning process is continuous. In order to meet the changing requirements of a professional society, students must be ready to improve their level of education independently, that is, to update and expand their knowledge, skills and abilities 
constantly. In connection with these changes in society, the focus is on self-development, personalized learning through the introduction and use of information and communication technologies in the educational process.

The analysis of professional literature shows that the pedagogical potential of ICT tools creates the preconditions for strengthening the educational process, as well as the methods focused on the intellectual development of students. The use of ICT in the educational process increases the effectiveness of the formation of universal skills and competencies, teaches you to plan and organize your own independent cognitive activity, which contributes to self-education.

\section{Conclusions}

The rapid development of information and communication technologies and the use of elearning have expanded the possibilities of the educational process and provided opportunities for the general development of students. Practice shows that the use of electronic educational resources improves students' perception and understanding of the issues that are under consideration and creates more comfortable conditions for learning. However, with the systematic use of electronic educational resources in the educational process in combination with traditional teaching methods and pedagogical innovations, the effectiveness of multilevel education has significantly increased. At the same time, there is a qualitative increase in educational results due to the simultaneous impact of several technologies.

The introduction of new information and communication technologies into the modern educational process contributes to the training of students of the highest quality. The use of multimedia in the educational process contributes to the development of logical thinking, the culture of intellectual work, the formation of students' skills of independent work, and also has a significant impact on the motivating field of the educational process.

The results of the study allow to conclude the following:

1. The analysis of the state of the discussed problem in the psychological, pedagogical and scientific and methodological literature shows that it is still urgent in the context of the introduction of new generation standards.

2. In the course of the study, the concepts of "e-learning" and "distance learning technology" were clarified.

3. As a result of the processing of statistical data, it was concluded that the use of information and communication technologies increases the effectiveness of training. This research does not exhaust all the aspects of the discussed problem, but can serve as a conceptual and theoretical basis for further scientific research.

\section{References}

1. I.A. Kolesnikova, Pedagogical Projecting, 288 (2019)

2. E.S. Polat, Distance Learning, 190 (2019)

3. T.Yu. Bystrova, The Introduction of an Open E-Learning System as a Factor in the Development of the Region, Economy of the Region, 4, 226-237 (2016)

4. V.I. Andreev, The Center for Innovative Technologies, 608 (2019)

5. O.A. Gorovaya, The Use of Distance Technologies in the Development of Teachers' Readiness for the Formation of Universal Educational Actions of Junior Schoolchildren, Scientific Support of the System of Advanced Training of Personnel, 3 (5), 80-84 (2018) 
6. A.V. Nevzorova, The Study of the Possibilities of the Informational Environment of an Educational Organization in the Professional Development of a Teacher, Education and Training, 1, 9-11 (2017)

7. V.F. Basharin, Pedagogical Technology: What Is It ?, Specialist, 9, 26-29 (2016)

8. E.I. Bulin-Sokolova, Using ICT in Education, Informational Society, 3/4, 119 (2018)

9. A.S. Krylova, Formation of ICT Competence in the Process of Implementing the Educational Model "The Inverted Learning”, Academy, 1 (4) (2016)

10. A.A. Kuznetsov, A.L. Semenov, About the Project of the Concept of the Educational Area "Informatics and Information Technologies", 17, 21 (2017)

11. D.Sh. Matros, School Informational Model, Computer Science and Education, 3, 1-8 (2018)

12. E-soft Development / website of the company for the development of distance courses. Access mode: http://www.weblearn.ru/ozentre\#

13. Going the Distance: Online Educational in the United States [Electronic resource]. Access mode: http: //olms.cte.jhu.edu/olms2 / data / ck / sites / 336 /files/goingthedistance.pdf 